\title{
Trajetórias de jovens pelas políticas sociais: garantia ou violação de direitos?
}

\author{
Erlayne Beatriz Félix de Lima Silva* (1) \\ Maria de Fatima Pereira Alberto (1) \\ Cibele Soares da Silva Costa (1) \\ Universidade Federal da Paraíba. João Pessoa, PB, Brasil
}

\begin{abstract}
Resumo: Este artigo tem como objetivo apresentar trajetórias de acesso às políticas sociais de jovens em cumprimento de medidas socioeducativas, em momento anterior ao cumprimento destas, numa cidade do estado da Paraíba. Busca-se compreender de que modo as políticas sociais brasileiras têm oportunizado trajetórias de garantia de direitos e de condições favoráveis para o desenvolvimento da população infanto-juvenil. A perspectiva teórica utilizada foi a psicologia histórico-cultural de Vigotski. Realizaram-se entrevistas com dez jovens, as quais foram investigadas por meio de análise de conteúdo temática. Os resultados revelaram que os jovens participantes desta pesquisa acessaram equipamentos pertencentes às políticas sociais de saúde, educação e assistência social. Entretanto, apesar desse acesso, estas políticas sociais não se apresentaram como ferramentas efetivas para proteção e garantia de seus direitos, pois não possibilitaram o rompimento com as trajetórias de desproteção vivenciadas por eles.
\end{abstract}

Palavras-chave: jovens, medidas socioeducativas, política social, desenvolvimento.

\section{Introdução}

Este artigo apresenta trajetórias de acesso às políticas sociais de jovens em cumprimento de medidas socioeducativas, em momento anterior ao cumprimento destas, em uma cidade localizada no estado da Paraíba. Tendo em vista a contradição exposta pela literatura de que os jovens têm se alternado entre papéis de vítimas e algozes da violência (Zappe \& Ramos, 2010), problematiza-se: quais são suas trajetórias pelas políticas sociais? De que modo tais políticas têm garantido os direitos da população infanto-juvenil? Quais as condições ofertadas pelas políticas sociais para o desenvolvimento desses jovens? Quais as implicações dessas trajetórias em seu desenvolvimento? E para a prática de atos infracionais?

As políticas sociais são entendidas neste trabalho como respostas do Estado para os conflitos entre capital e trabalho na sociedade capitalista, decorrentes da organização e reivindicação da classe trabalhadora por melhores condições de vida e necessárias à reprodução do modo de produção capitalista (Behring \& Boschetti, 2011). Apesar de desempenhar esse papel, a consolidação das políticas sociais no Brasil enquanto direito de todos os cidadãos só se deu com a promulgação da Constituição Federal de 1988, que determinou a criação de uma série de políticas sociais para efetivar os direitos por ela assinalados.

\footnotetext{
* Endereço para correspondência: erlayne.beatriz@gmail.com

1 Este trabalho foi realizado com apoio da Coordenação de Aperfeiçoamento de Pessoal de Nível Superior (CAPES). Código de Financiamento 001.
}

Entre estas políticas, destaca-se a criação do Estatuto da Criança e do Adolescente (ECA, Lei $\mathrm{n}^{\circ} 8.069$, de 13 de julho de 1990), principal marco legal destinado à infância e juventude brasileira, pois define o tratamento protetivo por meio da Doutrina da Proteção Integral, que se refere ao conjunto de legislações que regulamentam o atendimento e tratamento de crianças e adolescentes nas políticas sociais brasileiras (Jimenez \& Frasseto, 2015).

Além disso, o ECA reconhece crianças e adolescentes como sujeitos de direitos, o que implica no reconhecimento do dever do Estado em garantir a proteção social por meio de investimentos em políticas sociais protetivas que oportunizem as condições para seu pleno desenvolvimento. Portanto, conforme o artigo $4^{\circ}$ do ECA, as crianças e os adolescentes brasileiros passam a ter seus direitos fundamentais garantidos, sendo eles "os direitos referentes à vida, à saúde, à alimentação, à educação, ao esporte, ao lazer, à profissionalização, à cultura, à dignidade, ao respeito, à liberdade e à convivência familiar e comunitária" (Brasil, 1990a).

Para garantir esses direitos, é necessário criar políticas sociais específicas para essa parcela da população. Neste trabalho, elegem-se como as três principais áreas da política de atendimento à infância e juventude, as políticas sociais de saúde, educação e assistência social, que, de forma articulada, compõem o Sistema de Garantia de Direitos destinado ao público infanto-juvenil. Esse Sistema corresponde a um conjunto de instituições públicas, governamentais e não governamentais dos diferentes setores e políticas sociais que, de forma integrada e articulada, visam à proteção 
integral das crianças e jovens pelos eixos de promoção, defesa e controle social (Bauer, Carvalho, Stangherlim, \& Diniz, 2015).

O direito à saúde é operacionalizado pelo Sistema Único de Saúde (SUS), composto por uma rede regionalizada e descentralizada de serviços de saúde regidos pelos princípios da universalidade, integralidade e igualdade. Entre os serviços que fazem parte do SUS, encontram-se as Unidades Básicas de Saúde (UBS), hospitais, Unidades de Pronto Atendimento, Centros de Atenção Integral à Saúde e Núcleos de Apoio à Saúde da Família, os quais devem promover ações de prevenção, atenção e cuidado prioritário às necessidades da população infanto-juvenil, tais como aleitamento materno, assistência médica, odontológica e alimentar, entre outros (Brasil, 1990a, 1990b).

No que se refere ao direito à educação, esta é uma garantia guiada pela Lei de Diretrizes e Bases (LDB, Lei no 9.394, de 1996), a qual determina o ensino básico como obrigatório e gratuito para todos os cidadãos entre quatro e dezessete anos, distribuídos conforme as especificidades de desenvolvimento, em pré-escola, ensino fundamental e ensino médio, sendo ofertadas vagas em serviços como creches e escolas com responsabilidade compartilhada entre os diferentes níveis governamentais (Brasil, 1996).

Em relação à Política de Assistência Social, esta é norteada pela Lei Orgânica de Assistência Social (Loas, Lei no 8.742, de 1993) e pelo Sistema Único de Assistência Social (Suas), os quais estabelecem dois níveis de atenção: a proteção social básica e a proteção social especial, compostas por serviços e equipamentos como os Centros de Referência de Assistência Social (Cras), Centros de Referência Especializados de Assistência Social (Creas), instituições de acolhimento, serviços para jovens em cumprimento de medidas socioeducativas, Programa de Erradicação do Trabalho Infantil (Peti), Serviço de Convivência e Fortalecimento de Vínculos (SCFV), entre outros (Brasil,1993, 2004).

Desse modo, as políticas sociais anteriormente citadas se articulam no âmbito do Sistema de Garantia de Direitos, por meio dos eixos promoção, defesa e controle, compondo uma rede de serviços, equipamentos e programas integrados com o objetivo de garantir e proteger os direitos fundamentais das crianças e jovens, conforme determinado pelo ECA (Brasil, 1990a).

A criança e o adolescente gozam de todos os direitos fundamentais inerentes à pessoa humana, sem prejuízo da proteção integral de que trata esta Lei, assegurando-se-lhes, por lei ou por outros meios, todas as oportunidades e facilidades, a fim de lhes facultar o desenvolvimento físico, mental, moral, espiritual e social, em condições de liberdade e de dignidade. (Brasil, 1990a, artigo $3^{\circ}$ )

No que concerne ao funcionamento e efetivação dessas políticas, a literatura tem retratado que, apesar dos avanços nas legislações destinadas à proteção da população infanto-juvenil, ainda existe discrepância entre os ordenamentos jurídicos e sua aplicação como prática do Sistema de Garantia de Direitos na sociedade brasileira (Fonseca, Sena, Santos, Dias, \& Costa, 2013; Gurski, 2012). Isto é, as políticas para infância e juventude, atualmente, ainda trazem consigo traços assistencialistas perpassados pela perspectiva de controle e ordem social, marcada pela institucionalização e segregação da população atendida, gerando processos de criminalização e exclusão que vão na contramão da perspectiva da garantia de direitos e proteção social às crianças e jovens brasileiros (Gurski, 2012; Perez $\&$ Passone, 2010).

Tais entraves se apresentam como reflexos da constituição das políticas sociais numa sociedade baseada no modo de produção capitalista, que as utiliza como ferramentas paliativas para o enfrentamento da questão social, considerando que não é objetivo desse sistema erradicar as expressões da questão social que se referem ao conjunto de problemas sociais, econômicos e políticos decorrentes das contradições entre capital e trabalho numa sociedade capitalista (Yamamoto \& Oliveira, 2014), assim como a falta de acesso aos direitos sociais básicos - educação, saúde, moradia, alimentação, lazer, etc. -, que resulta em consequências negativas para a população, como trabalho infantil, prática de atos infracionais, desemprego, mendicância, exploração sexual, entre outros.

Além disso, historicamente, a questão social tem afetado principalmente os jovens que fazem parte da classe trabalhadora (Souza \& Paiva, 2012). Conforme discutem Leal \& Macedo (2017), o processo de criminalização das expressões da questão social se constitui como uma das caraterísticas centrais do sistema capitalista para lidar com as consequências da desigualdade social por ele perpetrada. Somado a isso, compreende-se que, nesse tipo de estrutura de sociedade, muitas vezes o próprio Estado, que deveria promover a garantia dos direitos da população, propaga a violência estrutural em suas instituições oficiais, assim como a precarização e o sucateamento das políticas sociais, contribuindo com projetos políticos e econômicos que reforçam os processos de desigualdade social (Azevedo, Amorim, \& Alberto, 2017).

No que diz respeito à população infanto-juvenil e à prática de atos infracionais, a partir do ECA, a transgressão praticada pelos adolescentes (correspondendo a pessoas na faixa etária entre doze e dezoito anos) é compreendida como ato infracional não passível de responsabilização penal, devendo o adolescente ser submetido à aplicação de medidas socioeducativas, que, segundo o artigo 112 do ECA, são: advertência, obrigação de reparar o dano, prestação de serviços à comunidade, liberdade assistida, inserção em regime de semiliberdade e internação em estabelecimento educacional. O objetivo dessas medidas se concentra na desaprovação da conduta infracional, na responsabilização pelo ato, na reinserção social e no fortalecimento dos vínculos afetivos, familiares e 
comunitários do jovem a quem se atribui a autoria de um ato infracional (Brasil, 1990a, 2012).

A literatura sobre os jovens a quem se atribui a autoria de atos infracionais aponta que o sistema socioeducativo insere, em sua maioria, os jovens pobres, oriundos das classes trabalhadoras, do sexo masculino, negros, com baixa escolaridade e que experienciaram variados processos de violações aos seus direitos fundamentais decorrentes da precariedade de investimentos em políticas sociais (Jimenez \& Frasseto, 2015; Siqueira \& Tavares, 2013; Souza \& Venâncio, 2011; Zappe \& Ramos, 2010), configurando-se como uma das expressões da questão social (Sartório \& Rosa, 2010).

A precarização das políticas sociais no âmbito das medidas socioeducativas, sejam estas de meio aberto ou fechado, refletem na perpetuação das desigualdades sociais pelo Estado, reforçando o discurso de criminalização dos jovens aos quais se atribui a prática de atos infracionais, em detrimento da análise dos múltiplos fatores históricos, sociais e econômicos que perpassam a relação dos jovens com a prática de atividades consideradas ilícitas (Azevedo et al., 2017).

Contudo, apesar das limitações, essas políticas são necessárias, pois são entendidas como as principais ferramentas mediadoras do desenvolvimento dos jovens das classes trabalhadoras, tendo em vista que elas são, para esses sujeitos, o espaço social público responsável por oportunizar as condições para seu desenvolvimento (Gonçalves, 2010).

O desenvolvimento aqui é entendido, a partir de Vigotski (1984/2007), como um processo global, não linear, resultante das relações sociais que os sujeitos estabelecem com outros, com a sociedade e com a cultura, sendo ao mesmo tempo constituído e constituinte do meio no qual está inserido, caracterizando-se por transformações qualitativas e complexas de uma forma de comportamento em outra, que se dão pela mediação estabelecida entre sujeitos e contexto.

A mediação se caracteriza como intervenção que provoca transformações e potencializa o desenvolvimento dos sujeitos, através das quais se apropriam dos produtos concretos e abstratos produzidos pela humanidade ao longo da história. Essa aquisição, que ocorre dialeticamente, propicia o desenvolvimento das funções psíquicas desses indivíduos (Martins, 2016).

Portanto, a mediação se constitui como aspecto essencial para promover o desenvolvimento humano, pois tem a função de organizar as estruturas psíquicas pelas quais os sujeitos se apropriam de novas formas de comportamento (Vigotski, 1984/2007). Além disso, o desenvolvimento resultará da natureza e qualidade das mediações interpostas entre sujeitos e suas condições de vida (Martins, 2016). Com isso, as políticas sociais enquanto ferramentas mediadoras para o desenvolvimento dos indivíduos da classe trabalhadora serão as principais responsáveis por proporcionar os elementos materiais concretos que farão a mediação entre as condições de vida e o desenvolvimento dos jovens.

Diante disso, parte-se do pressuposto de que as políticas sociais no Brasil são as ferramentas legais responsáveis por garantir e promover o desenvolvimento da população infanto-juvenil. No entanto entende-se que, apesar de essa parcela da população acessar equipamentos pertencentes a tais políticas em suas trajetórias de vida, essas não têm efetivado a garantia dos direitos desses sujeitos nem oportunizado condições favoráveis para seu desenvolvimento.

Somado a isso, busca-se, com este trabalho, contribuir com o debate teórico acerca da juventude a quem se atribui a prática de atos infracionais à luz da psicologia histórico-cultural para compreender e discutir os aspectos que se constituem como elementos mediadores para o desenvolvimento desses jovens, que repercutirão na constituição da subjetividade destes e em suas formas de se expressarem socialmente.

\section{Método}

Este estudo se trata de uma pesquisa qualitativa na qual foram realizadas entrevistas com jovens em cumprimento de medidas socioeducativas de internação com o intuito de compreender o acesso desses jovens as políticas sociais em suas trajetórias de vida. A pesquisa qualitativa se constitui como uma abordagem de investigação que reconhece a complexidade dos fenômenos nas ciências humanas e sociais, e busca captar os aspectos subjetivos da realidade social, possibilitando análises que são singulares e contextualizadas (Minayo, 2014).

\section{Participantes}

Participaram deste estudo dez jovens, com idades entre quinze e dezessete anos, que estavam em cumprimento de medidas socioeducativas de internação em uma cidade do estado da Paraíba. Os participantes foram selecionados pelo critério de conveniência e acessibilidade a eles.

\section{Instrumentos}

Foram realizadas entrevistas abertas e individuais com cada participante, as quais contemplaram as experiências e trajetórias de acesso às políticas sociais de saúde, educação e assistência social dos entrevistados durante sua infância, além dos aspectos relacionados ao contexto social no qual estavam inseridos.

\section{Procedimentos}

Inicialmente, a pesquisa foi submetida ao Comitê de Ética em Pesquisa da Universidade Federal da Paraíba, conforme as recomendações da Resolução no 466/2012 do Conselho Nacional de Saúde. Após aprovação do comitê 
pelo Certificado de Apresentação para Apreciação Ética (CAAE) $\mathrm{n}^{\mathrm{0}}$ 51447915.9.000.5188, estabeleceram-se contatos com as instituições responsáveis pela execução das medidas socioeducativas de internação, para explicar os objetivos da pesquisa e solicitar autorização para sua realização.

Com o aceite das instituições responsáveis pela execução das medidas socioeducativas, foram realizadas conversas com os jovens com o intuito de explicar o objetivo da pesquisa e convidá-los a participar deste estudo. As entrevistas aconteceram entre os meses de maio e julho de 2016, após a devida autorização dos participantes e da instituição responsável, mediante as assinaturas dos termos de consentimento livre e esclarecido.

\section{Análises dos dados}

As entrevistas foram submetidas à análise de conteúdo temática baseada em Minayo (2014), composta pelas seguintes etapas: organização do material, leitura flutuante das entrevistas, codificação do material em temas e categorias a partir do critério de ausência ou presença dos temas na fala. Em seguida, o material e a análise dos dados foram descritos à luz do referencial teórico adotado neste estudo.

\section{Resultados e discussões}

Os resultados e as discussões foram organizados em três tópicos que contemplam a caracterização dos participantes e do contexto social, a análise temática das entrevistas e as implicações do acesso às políticas sociais para o desenvolvimento dos jovens participantes da pesquisa.

\section{Caracterização dos participantes e do contexto social}

Os participantes deste estudo tinham entre quinze e dezessete anos; a maioria encontrava-se em cumprimento de medida socioeducativa de internação há aproximadamente dois anos. A escolaridade dos jovens ao adentrar a instituição variava entre o segundo ano do ensino fundamental e o primeiro ano do ensino médio. Os jovens estavam matriculados e frequentando a escola durante o cumprimento da medida socioeducativa, sendo que um deles havia concluído o ensino médio. Tais dados revelam o que a literatura aponta acerca do perfil de jovens em cumprimento de medida socioeducativa, os quais, em sua maioria, não apresentam o grau de escolaridade esperado para sua idade, pois não vivenciaram a escola como ferramenta primordial de garantia de direitos, de inserção na sociedade e na cultura, e de aquisição dos bens historicamente produzidos por estas (Jimenez \& Frasseto, 2015; Souza \& Venâncio, 2011; Zappe \& Ramos, 2010).

No que diz respeito aos vínculos familiares antes da internação em unidade socioeducativa, os participantes residiam em sua maioria com mãe, irmãos, pai, padrastos e avós maternos ou paternos. Ressalta-se, nesse aspecto, a presença da mãe e da avó como as principais responsáveis pela família. A maioria dos jovens residia em bairros localizados nas periferias da cidade. Além disso, também apresentaram relatos de trabalho infantil, que esteve presente na fala de cinco entre os dez participantes. Tais elementos se apresentam como expressões da questão social à qual estes sujeitos estiveram expostos durante a infância (Sartório \& Rosa, 2010; Yamamoto \& Oliveira, 2014).

\section{Trajetórias de acesso às políticas sociais}

A análise temática das falas dos jovens possibilitou compreender suas trajetórias de acesso às políticas sociais por meio de equipamentos educacionais, como a escola; equipamentos de saúde, como UBS e hospitais; e equipamentos de assistência social, como o Peti e instituição de acolhimento.

No que se refere aos aspectos relacionados ao acesso à escola, as categorias "Frequentava a escola", "Fugia da escola" e "Impedimentos para frequentar a escola" revelaram que a maioria dos jovens frequentou instituições de ensino ao longo de sua infância, apresentando interesses e recusas para sua permanência na instituição. Além disso, observou-se que os sujeitos vivenciaram situações que foram consideradas como impeditivas à sua frequência ao espaço escolar. A fala a seguir ilustra essas categorias:

Estudava num colégio. Depois de uma temporada já fumando maconha, foram atrás de mim no colégio, deixei de estudar. ... Era bom, né, ia para lá estudar. Quando foi depois, os caras foram lá tentar tirar minha vida lá, eu parei de ir pro colégio. (Participante 4)

Observou-se que a escola, entendida como a instituição oficial e socialmente responsável pela inserção das crianças e jovens na sociedade e na cultura, por meio da qual os sujeitos são colocados a fazer suas próprias escolhas, a se posicionar socialmente $\mathrm{e}$ a construir seus respectivos projetos de vida (Souza \& Venâncio, 2011), não tem se apresentado como espaço efetivo para a promoção e garantia dos elementos necessários para apropriação das aquisições históricas e materiais construídas pelos homens e pela cultura, para os jovens das classes trabalhadoras.

No que diz respeito ao acesso à política social de saúde, as falas dos entrevistados demonstraram que eles foram atendidos em UBSs (identificadas por eles como "postos de saúde") e em hospitais. Ao se referir aos espaços pelos quais passaram, as falas dos jovens revelaram avaliações que apontaram para a demora no atendimento e à falta de profissionais e medicações, conforme se pode observar no relato a seguir: 
Às vezes eu ia pro posto, às vezes minha mãe comprava um remédio pra eu. ... Demorava que só, mas tinha vez que chamava, mas tinha vez que não tinha nem médico, nem nada. A gente ia pra casa mesmo assim. Esperar melhorar. . . quando tinha dinheiro, comprava um remédio. (Participante 3)

Percebeu-se que o acesso à política social de saúde se deu a partir de necessidades emergenciais, contrariamente ao que é preconizado pela literatura e pelas legislações de saúde, que enfatizam aspectos de promoção e prevenção na atuação em saúde, bem como a articulação entre as várias políticas sociais que compõem o sistema de garantia de direitos, como educação e assistência social, tendo em vista uma atuação integrada em saúde (Brasil, 1990b; Fonseca et al., 2013).

Em relação ao acesso à política de assistência social, os jovens relevaram que acessaram o Peti e passaram por instituições de acolhimento. A passagem pelo Peti foi relatada como momento de recreação e alternativa para que não ficassem pelas ruas, conforme se verifica no relato a seguir:

Fazia Peti, Programa do Trabalho Infantil. . . Lá no Peti, é o Programa do Trabalho Infantil pros adolescentes não tá na rua, ai eu fazia lá no Peti, fazia percussão, informática, fazia isso. O Peti, era negócio de percussão, informática, lá era pra aprender como se mexia no computador, e percussão é aquele negócio que o cara batia no pau e pá, e flauta. Também tinha flauta, aula de flauta. Eu achava legal e, ao mesmo tempo, não achava. Tinha dia que eu não queria participar e eu ficava lá só parado. Dava hora de jogar bola e pronto. E duas horas, quando dava duas horas, ia pra casa, minha mãe ia me buscar, e o cara podia só sair quando a mãe do cara fosse buscar o cara. Sozinho o cara não podia sair, não. (Participante 2)

Já a inserção em instituição de acolhimento foi relatada como um momento no qual os jovens foram retirados do convívio familiar e tiveram acesso a atividades pertinentes ao seu desenvolvimento como brincar, estudar e participar de atividades de lazer. Todavia essa inserção não foi suficiente para construir projetos de vida que permitissem a inserção dos sujeitos em atividades profissionalizantes que apresentassem saídas diferenciadas das já vivenciadas, como a prática de atos infracionais.

Foi, eu e meu irmão, ele tá lá de novo. Ele tá lá e eu tô aqui. Quando a gente chegou lá, eles começaram a explicar: "olhe aqui, a gente é como sua familia, se precisar de qualquer coisa, pode chamar eu". A gente estudava lá também. Eles começaram a ensinar a gente como era que fazia as coisas, forrar a nossa própria cama, fazer uma faxina lá, pra nós começar a desenhar, fazer lição de casa, esses negócio, lá. No final de semana ia pra praia, nós ia pra praia com elas. Nós ia estudar. Eu fui com mais ou menos nove anos, fui com nove anos, aí passei seis mês da primeira vez, ai peguei e voltei de novo e sai com onze anos. Eu sai assim, só pensando no crime, só pensando no crime, em querer ajudar a minha vó. Só que não tinha condição, eu pequeno ainda. Ai eu tentei arrumar um jeito, ficava lá mais os meninos. Foi sair, saindo e pensando no negócio do crime. Mas minha vó sempre me deu conselho. Minha vó sempre me deu conselho. (Participante 5)

Observa-se que a inserção do jovem em instituições de acolhimento se caracteriza por colocá-lo numa dinâmica complexa de relações na medida em que lida, ao mesmo tempo, com a tentativa de proteção dos sujeitos e com a quebra dos vínculos familiares, buscando ofertar ações que promovam o desenvolvimento das crianças e dos adolescentes, mas que, por outro lado, devido à precariedade de investimentos nas políticas sociais, não possibilitam a construção de novos projetos de vida (Perez \& Passone, 2010).

Além disso, contraditoriamente, as falas dos entrevistados revelaram ausência de equipamentos educativos e recreativos nos bairros em que estavam inseridos durante a infância. Essa ausência de serviços que ofertassem atividades lúdicas, esportivas ou recreativas ocasionou a busca por atividades em outros bairros, a formação de grupos e caracteriza uma das expressões da questão social à qual os jovens estiveram expostos. A fala a seguir ilustra essa situação:

Deixei de morar na minha casa, que eu não podia ir mais pra aquele canto. Se fosse, os cara chegava pra matar. Tive que morar em outro canto, no meio de um bocado de bicho, assim, que era mais violento do que eu, né, que não tinha medo, pá. Chegava lá e fazia mesmo. (Participante 4)

Percebeu-se que os bairros onde os jovens estão inseridos foram caracterizados pela falta de infraestrutura e presença do tráfico de drogas, elementos que se constituíram como mediadores para o desenvolvimento dos adolescentes, os quais perpassaram sua constituição enquanto sujeitos, resultando em desdobramentos para o desenvolvimento (Vigotski, 1984/2007), como o afastamento da família, a inserção em contextos de violência, o trabalho infantil, entre outros.

Desse modo, nota-se que as trajetórias dos jovens pelas políticas sociais revelaram que estas têm se caracterizado por ações localizadas e fragmentadas, atendendo a necessidades específicas de forma descontextualizada, expressas pela ausência de oferta de condições plenas para o desenvolvimento saudável dessas crianças e jovens. Isso contradiz as legislações brasileiras que determinam prioridade no atendimento a essa parcela 
da população, tendo em vista que são considerados sujeitos em situação peculiar de desenvolvimento (Brasil 1990a, 1990b, 1993, 1996, 2004).

\section{O acesso às políticas sociais e as implicações para o desenvolvimento dos jovens}

A partir das trajetórias de acesso às políticas sociais dos jovens participantes desta pesquisa, pôde-se observar que estes tiveram acesso a alguns equipamentos das políticas sociais de garantia de direitos das áreas de educação, saúde e assistência social. Entretanto, apesar do acesso, as políticas sociais não têm se apresentado como ferramentas efetivas para proteção e garantia dos direitos dos indivíduos, tendo em vista que, mesmo passando por tais políticas, estas não conseguiram romper com a trajetória de desproteção às quais os jovens das classes trabalhadoras têm vivenciado (Siqueira \& Tavares, 2013). Portanto os dados revelam que as práticas estabelecidas nas políticas sociais não dispõem de mecanismos pedagógicos que proporcionem a construção de novas trajetórias de vida para os jovens, de modo que, mesmo tendo acessado essas políticas durante a infância, os entrevistados estavam cumprindo medidas socioeducativas.

No que se refere à ineficiência das políticas sociais e do sistema de garantia de direitos em promover a proteção à infância e juventude, esta pode ser compreendida como reflexo da constituição dessas políticas numa sociedade baseada no modo de produção capitalista, segundo o qual se prioriza a (des)responsabilização do Estado diante das expressões da questão social, por meio da precariedade e fragmentação nos investimentos e nas ações relacionadas a elaboração e execução de políticas sociais (Gonçalves, 2010). Segundo Perez \& Passone (2010), essa ineficiência se apresenta pelo déficit de atendimentos ofertados em relação às desigualdades econômicas e sociais presentes na sociedade brasileira, atreladas à inconstância do estado democrático.

Desse modo, observa-se que, no contexto das sociedades capitalistas, as políticas sociais são criadas enquanto mecanismos paliativos e não visam à erradicação das expressões da questão social provenientes dos conflitos entre capital e trabalho, como o desemprego e a falta de acesso às condições de vida necessárias ao bem-estar da população, como moradia, alimentação, educação e saúde (Behring \& Boschetti 2011; Yamamoto \& Oliveira, 2014). Esses aspectos apresentam consequências para o desenvolvimento das crianças e dos jovens das classes trabalhadoras, bem como ao atendimento que lhes é destinado pelas políticas sociais, pois os elementos que constituem essas políticas serão caracterizados pela fragmentação das ações e insuficiência de equipamentos e serviços, além da precarização das condições de trabalho dos profissionais inseridos nessas políticas.

Diante do exposto, percebe-se que a não efetivação das políticas sociais protetivas para infância e juventude das classes trabalhadoras, por meio da não oferta de equipamentos recreativos e educativos suficientes e eficazes, apresenta consequências para seu desenvolvimento, como o término precoce da infância ou a não experimentação de atividades pertinentes a essa etapa, como a aquisição das ferramentas psíquicas necessárias ao seu desenvolvimento por meio da escolarização e obtenção dos conhecimentos produzidos pela humanidade ao longo da história das sociedades e culturas (Martins, 2016; Vigotski, 1984/2007). Desse modo, não são oferecidas as condições materiais que possibilitem aos sujeitos das classes trabalhadoras vivenciarem a experiência da infância com dignidade (Gurski, 2012).

Destarte, as trajetórias de acesso às políticas sociais dos jovens participantes desta pesquisa apontam para a ineficiência na proteção e garantia dos direitos das crianças e adolescentes inseridos nessas políticas, como forma de prevenção ou cessação às situações de violações de direito, tendo em vista que, mesmo tendo acessado alguns equipamentos de tais políticas, esses sujeitos apresentaram em sua trajetória vivências de negação de direitos e ausência de condições favoráveis ao seu desenvolvimento. Esses elementos não permitem que os jovens se enxerguem como sujeitos de direitos, resultando em processos de exclusão e criminalização da juventude das classes trabalhadoras (Azevedo et al., 2017; Siqueira \& Tavares, 2013; Souza \& Paiva, 2012; Souza \& Venâncio, 2011), manifestando-se, por exemplo, por meio do trabalho infantil e da prática de atos infracionais.

Portanto, as políticas sociais entendidas neste estudo enquanto ferramentas mediadoras essenciais para o desenvolvimento das crianças e jovens das classes trabalhadoras não estão ofertando as condições necessárias para apropriação dos bens sociais e culturais produzidos historicamente pela humanidade, negando a esses sujeitos o desenvolvimento de suas potencialidades humanas (Gonçalves, 2010; Martins, 2016).

Compreende-se, a partir da perspectiva teórica adotada, que a garantia de condições favoráveis para o desenvolvimento dos jovens, como o acesso à educação, saúde, moradia, lazer, profissionalização, entre outros, são aspectos essenciais para constituição dos indivíduos a partir da noção de sujeito de direitos.

Entretanto, é perceptível que as trajetórias dos jovens participantes desta pesquisa foram marcadas pela não garantia destes direitos, o que se expressa com a exposição à violência, o não acesso a políticas protetivas efetivas, a inserção no trabalho infantil e a prática de atos infracionais. Esses aspectos se constituíram como os elementos mediadores para o desenvolvimento desses jovens, situações de desenvolvimento que também são compartilhadas por uma parcela significativa da população brasileira que advém das classes trabalhadoras, as quais, imersas numa sociedade capitalista, ficam expostas a situações de desproteção social que culminam em processos de criminalização desses jovens. 


\section{Algumas considerações}

Diante do objetivo deste estudo de apresentar as trajetórias de acesso às políticas sociais de jovens em cumprimento de medidas socioeducativas de internação antes do ato infracional, conclui-se que esta pesquisa possibilitou compreender que o percurso dos participantes pelas políticas sociais demonstrou que estas têm se caracterizado por ações localizadas e fragmentadas, atendendo a necessidades específicas de forma descontextualizada, expressas pela não oferta de condições plenas para o desenvolvimento saudável de crianças e jovens, contradizendo as legislações brasileiras que determinam prioridade no atendimento a esta parcela da população, considerada em situação peculiar de desenvolvimento.

Nesse cenário, ressalta-se a importância de compreender o desenvolvimento dos sujeitos por meio de suas trajetórias pelas políticas sociais, a partir das condições materiais de vida que lhes foram postas pela sociedade e pela cultura, adotando como aporte teórico a psicologia histórico-cultural de Vygotsky. Somado a isso, pretende-se, com este estudo, contribuir com a produção teórica acerca dos jovens a quem se atribui a autoria de atos infracionais, a partir da compreensão dos elementos concretos (históricos, sociais e econômicos) que perpassaram o desenvolvimento desses sujeitos. Para isso, buscou-se evidenciar as condições materiais colocadas em suas trajetórias de vida e nos contextos sociais em que estavam inseridos, tais como a violência, o trabalho infantil e a prática de atos infracionais, compreendendo que estes foram os elementos mediadores na constituição da subjetividade desses sujeitos, decorrentes do modo de produção capitalista, desigual e excludente.

Por fim, reitera-se a necessidade de acompanhamento e proposição de políticas sociais destinadas às crianças e aos jovens brasileiros para que sejam garantidos seus direitos fundamentais, conforme determinado nos ordenamentos jurídicos do país.

\section{Youth trajectories for social policies: ensuring or violating rights?}

Abstract: This article presents the trajectories of young people regarding access to social policies in compliance with social and educational measure services in order to understand how Brazilian social policies have an opportunistic trajectory of guaranteeing rights and favorable conditions for the development of children and adolescents. The theoretical framework used was the cultural-historical psychology of Vigotski. Interviews were conducted with ten young people and then analyzed through Thematic Content Analysis. The results revealed that the young participants of this research accessed the actions promoted by the social policies of health, education and social assistance. However, despite this access, these social policies didn't present themselves as effective tools for the protection and guarantee of the rights of these young people, since even though young people have gone through such policies, they have not been able to break with the trajectories of lack of protection to which they have been experienced.

Keywords: youth, social and educational measure services, social policy, development.

\section{Trayectorias de jóvenes en las políticas sociales: ¿garantía o violación de derechos?}

Resumen: Este artículo tiene como objetivo presentar las trayectorias de acceso a las políticas sociales de jóvenes en cumplimiento de medidas socioeducativas, en un momento anterior al cumplimiento de las medidas en una ciudad del estado de Paraíba. Se busca comprender de qué modo las políticas sociales brasileñas han potenciado las trayectorias de garantía de derechos y de condiciones favorables para el desarrollo infanto-juvenil. La perspectiva teórica utilizada fue la psicología histórico-cultural de Vigotski. Se realizaron entrevistas con diez jóvenes, las cuales fueron analizadas por medio del análisis de contenido temático. Los resultados revelaron que los jóvenes participantes en esta investigación accedieron a acciones promocionadas por las políticas sociales de salud, educación y asistencia social. Sin embargo, a pesar de este acceso, estas políticas sociales no se presentaron como herramientas efectivas para protección y garantía de los derechos de estos jóvenes, teniendo en cuenta que, incluso habiendo pasado por tales políticas, estas no pudieron romper con las trayectorias de desprotección a las que ellos pasaron.

Palabras clave: jóvenes, medidas socioeducativas, política social, desarrollo.

\section{Trajectoires des jeunes par les politiques sociales : garantie ou violation des droits ?}

Résumé : Cet article vise à présenter les trajectoires d'accès aux politiques sociales des jeunes dans le respect des mesures socioéducatives, précédentes a leurs accomplissements, dans une ville de l'état de Paraíba. Basé sur la théorie historico-culturelle 
de Vigotski, nous cherchons à comprendre comment les politiques sociales brésiliennes favorisent la garantie des droits et les conditions favorables au développement de la population infanto-juvénile. Des entretiens ont été menés avec dix jeunes, qui ont fait l'objet d'une analyse du contenu thématique. Les résultats ont révélé que les jeunes participants ont accédé aux équipements appartenant aux politiques sociales de santé, d'éducation et d'assistance sociale. Cependant, malgré cet accès, ces politiques sociales ne se sont pas présentés comme outils efficaces de protection et de garantie de leurs droits, étant donné que, bien qu'ayant subi de telles politiques, ces jeunes n'ont pas pu rompre avec les trajectoires de déprotection auxquelles ils étaient soumis.

Mots-clés : jeunes, mesures socio-éducatives, politique sociale, développement.

\section{Referências}

Azevedo, C. R. S., Amorim, T. R. S., \& Alberto, M. F. P. (2017). Adolescência e ato infracional: violência institucional e subjetividade em foco. Psicologia: Ciência e Profissão, 37(3), 579-594. doi: 10.1590/1982-3703003312016

Bauer, C., Carvalho, L., Stangherlim, R., \& Diniz, C. (2015). Crianças, adolescentes e jovens em condição de vulnerabilidade no Brasil contemporâneo: desafios e possibilidades de uma educação em direitos humanos. Revista Educación y Desarrollo Social, 9(1), 56-69. Recuperado de https://goo.gl/GkksRp

Behring, E. R., \& Boschetti, I. (2011). Política social: fundamentos e história (9a ed.). São Paulo, SP: Cortez.

Brasil. (1990a). Lei $n^{\circ} 8.069$, de 13 de julho de 1990. Dispõe sobre o Estatuto da Criança e da Adolescência e dá outras providências. Recuperado de https://bit.ly/2ZfWFCm

Brasil. (1990b). Lei $n^{\circ} 8.080$, de 19 de setembro de 1990. Dispõe sobre as condições para a promoção, proteção e recuperação da saúde, a organização e o funcionamento dos serviços correspondentes e dá outras providências. Recuperado de https://bit.ly/32athiO

Brasil (1993). Lei no 8.072, de 7 de setembro de 1993. Dispõe sobre a organização da Assistência Social e dá outras providências. Recuperado de https://bit.ly/2Gzxp3u

Brasil (1996). Lei $n^{\circ}$ 9.394, de 20 de dezembro de 1996. Estabelece as diretrizes e bases da educação nacional. Recuperado de https://bit.ly/3m5np2u

Brasil (2004). Politica Nacional de Assistência Social. Brasília, DF: Ministério do Desenvolvimento Social e Combate à Fome.

Brasil (2012). Lei no 12.594, de 18 de janeiro de 2012. Institui o Sistema Nacional de Atendimento Socioeducativo (Sinase), regulamenta a execução das medidas socioeducativas destinadas a adolescente que pratique ato infracional. Recuperado de https://bit.ly/3igJOYk

Fonseca, F. F., Sena, R. K. R, Santos, R. L. A., Dias, O. V., \& Costa, S. M. (2013). As vulnerabilidades na infância e adolescência e as políticas públicas brasileiras de intervenção. Revista Paulista de Pediatria, 31(2), 258-264. doi: 10.1590/S0103-05822013000200019

Gonçalves, M. G. M. (2010). O campo social das políticas públicas e sua dimensão subjetiva. In M. G. M.
Gonçalves, Psicologia, subjetividade e politicas públicas (pp. 31-76). São Paulo, SP: Cortez.

Gurski, R. (2012). O lugar simbólico da criança no Brasil: uma infância roubada? Educação em Revista, 28(1), 61-78. doi: 10.1590/S0102-46982012000100004

Jimenez, L., \& Frasseto, F. A. (2015). Face da morte: a lei em conflito com o adolescente. Psicologia \& Sociedade, 27(2), 401-414. doi: 10.1590/1807-03102015v27n2p404

Leal, D. M., \& Macedo, J. P. (2017). A penalização da miséria no Brasil: os adolescentes "em conflito com a lei". Textos \& Contextos, 16(1), 128-141. doi: 10.15448/1677-9509.2017.1.24550

Martins, L. M. (2016). Psicologia histórico-cultural, pedagogia histórico-crítica e desenvolvimento humano. In L. M. Martins, A. A. Abrantes, \& M. G. D. Facci (Orgs.), Periodização histórico-cultural do desenvolvimento psíquico: do nascimento à velhice (pp. 13-34). Campinas, SP: Autores Associados.

Minayo, M. C. S. (2014). O desafio do conhecimento: pesquisa qualitativa em saúde. (14a ed.). São Paulo, SP: Hucitec.

Perez, J. R. R., \& Passone, E. F. (2010). Políticas sociais de atendimento às crianças e aos adolescentes no Brasil. Cadernos de Pesquisa, 40(10), 649-673.

Sartório, A. T., \& Rosa, E. M. (2010). Novos paradigmas e velhos discursos: analisando processos de adolescentes em conflito com a lei. Serviço Social \& Sociedade, 103, 554-575. doi: 10.1590/S0101-66282010000300008

Siqueira, L. A. R., \& Tavares, G. M. (2013). O menino que queria ser gente. . . Um estudo da história de vida de adolescentes em conflito com a lei. Estudos e Pesquisas em Psicologia, 13(3), 1039-1067. Recuperado de https://goo.gl/ZfvbVA

Souza, C., \& Paiva, I. L. (2012). Faces da juventude brasileira: entre o ideal e o real. Estudos de Psicologia (Natal), 17(3), 353-360. doi: 10.1590/S1413-294X2012000300002

Souza, V. T., \& Venâncio, M. M. R. (2011). Os sentidos atribuídos à medida socioeducativa de liberdade assistida por jovens em conflito com a lei e seus socioeducadores. Psicologia da Educação, 32, 163-185. Recuperado de https://goo.gl/DQhy5r 
Vigotski, L. S. (2007). A formação social da mente: o desenvolvimento dos processos psicológicos superiores (7a ed.). São Paulo, SP: Martins Fontes. (Trabalho original publicado em 1984)

Yamamoto. O. H., \& Oliveira, I. F. (2014). Definindo o campo de estudo: as políticas sociais brasileiras. In I. F. Oliveira \& O. H. Yamamoto (Orgs.), Psicologia e políticas sociais: temas em debate (pp. 22-45). Belém, PA: UFPA.
Zappe, J. G., \& Ramos, N. V. (2010). Perfil de adolescentes privados de liberdade em Santa Maria/ RS. Psicologia \& Sociedade, 22(2), 365-373. doi: 10.1590/S0102-71822010000200017

Recebido: 22/09/2017

Revisado: 04/10/2019

Aprovado: 13/08/2020 